\title{
Assessment of using synthetic polymers in dewatering of sewage sludge
}

\begin{abstract}
This study was carried out to identify the optimum dosage of different types of polymer for sewage sludge conditioning to achieve high dewaterability. The sludge conditioners used in this study were synthetic polymers; cationic polymer (Magnafloc LT 22S), anionic polymers (Magnafloc LT 25 and Magnafloc LT27), and nonionic polymer (Magnafloc LT 20). Sewage sludge samples were collected from the holding tank of the treatment plant located at Taman Tun Dr Ismail, state of Selangor, Malaysia. Different laboratory tests were carried out to determine the effectiveness of each polymer in conditioning the sewage sludge and to obtain the best conditioner. In this study, the optimum conditions for sludge dewatering were determined from the results of laboratory experiments conducted on polymers with different dosages, mixing speeds, and mixing durations. Laboratory experiments conducted for this purpose include capillary suction time (CST), specific resistance to filtration (SRF), and zeta potential. Measurement of CST and SRF on the cationic polymer showed that the optimum condition was obtained when mixing duration was $4.5 \hat{\mathrm{A}} \mathrm{min}$, polymer dosage at $5.3 \hat{\mathrm{A}} \mathrm{mg} / \mathrm{L}$ and mixing speed of $83 \hat{\mathrm{A}} \mathrm{rpm}$. The zeta potential values indicated cationic polymer managed to reduce the charge; however, the anionic polymers were not effective in causing any neutralization. At optimum condition, the zeta potential values are expected to be near to zero.
\end{abstract}

Keyword: Dewatering; Optimum dosage; Sewage sludge; Synthetic polymers 